\title{
La Luz: una villa contemporánea para Avilés
}

\author{
Carmen Adams Fernández
}

RESUMEN. El barrio de La Luz en Avilés se levantó a partir de 1957 para dar alojamiento a los trabajadores de la nueva factoría siderúrgica: El proyecto inicial, inspirado en modelos del Movimiento Moderno, con zonas ajardinadas y edificios cruciformes, se fue transformando y abaratando progresivamente. Al final, quedo convertido en un conjunto de bloques impersonales, carentes de cualquier tipo de equipamiento y segregados de la ciudad.

Palabras clave: La Luz, Urbanismo, Avilés, Le Corbusier, ENSIDESA

ABSTRACT. The neighborhood of LA LUZ in Avilés raised from 1957 to give lodging to the workers of the new steel factory. The initial project, inspired in models of the Modern Movement, with garden zones and cross formeé buildings, went itself transforming and cheapening progressively. The result was an assembly of impersonal blocks lacking of any type of equipment and segregated of the city.

Key words: La Luz, Town planning, Avilés, Le Corbusier, ENSIDESA

La imprevisión de las autoridades para hacer frente a las oleadas de población que llegaron a Avilés a partir de la construcción de la gran factoría durante la década de los 50, dio lugar a barbaridades urbanísticas diversas. Entre ellas la de La Luz es reseñable, porque no fue fruto del azar, sino consecuencia de una operación especulativa con proyecto global incluido. Incluso podríamos decir que se trató casi de un engaño; porque la relación que pueda existir entre la propuesta inicial y el resultado final es pura coincidencia.

Torres cruciformes exentas, arbolado, equipamientos, previsiones de futuro para el tráfico rodado, conexión con la fábrica... Todo esto era el proyecto del barrio de La Luz y no era poco. En realidad cumplía las máximas que Le Corbusier propugnara para sus Principios de Urbanismo expresados en la Carta de Atenas. Se trataba de zonificar, al modo que Garnier ya anticipara, las funciones de la ciudad. Funciones que no eran otras que residencia, ocio, trabajo y tránsito.

Y no es sólo esta relación conceptual la que se evidencia entre el proyecto nunca ejecutado para un nuevo Avilés y los planteamientos de Le Corbusier. Además está la elección de algo tan llamativo formalmente como las torres cruciformes exentas, que ya el arquitecto suizo había propuesto en su Plan Voisin para París en 1925, concreción de las teorías expuestas en su Villa Contemporánea.

Es destacable como no será éste el único ejemplo asturiano que elija como modelo el proyecto del arquitecto suizo. Así, en el Polígono de las 1.500 de Gijón que data de 1956, encontramos un planteamien- 
to similar en la elección de bloques cruciformes ${ }^{1}$. Además, en éste hay otras referencias al Movimiento Moderno, más cercanas a los barrios de Gropius. El proyecto, ejecutado entre 1958 y 1961, corresponde a los arquitectos Avelino Díaz y FernándezOmaña, Miguel Díaz Negrete, Juan Manuel del Busto y J. Muñiz Muñiz.

Todo ello evidencia como se conocían y estaban vigentes durante estos años en nuestra región los postulados funcionalistas de urbanismo progresista. Y esto estará en la base de los conjuntos de edificios exentos en terrenos que así quedan anexionados a la ciudad con peor o mejor fortuna.

Es interesante saber entonces qué pasó para que el barrio de La Luz se convirtiera en lo que hoy conocemos, nada más lejos de la ciudad soñada por el Movimiento Moderno. Pero, también merece la pena detenerse a analizar los modelos que inspiraron tal propuesta que sobre el papel quedó, y que de no ser por la certeza de que se trató de una operación especulativa, podríamos vernos tentados a calificar de utopía.

Es preciso destacar que la elección de fórmulas emanadas directamente del Movimiento Moderno va a ser habitual en la construcción de polígonos residenciales de nuevo cuño para alojar población obrera en la España franquista. Esto se explica por la indefinición real del Régimen y la inconsistencia de las teorías arquitectónicas y urbanísticas grandilocuentes emanadas del poder central.

$\mathrm{Y}$ es que un aspecto característico de las viviendas de promoción pública de esta etapa (y que cobra gran relevancia si se considera que estas actuaciones definieron

\footnotetext{
${ }^{1}$ Hay un interesante trabajo inédito sobre el Polígono de las 1.500, realizado por Aitor Casal Matías y Diego Ruiz de la Peña Ruiz.
}

los nuevos espacios de ciudad que eran distintos a los de la ciudad tradicional), es su elección formal, relacionada con planteamientos de la ciudad-jardín y del Funcionalismo.

En este sentido es preciso tener en cuenta que el Instituto Nacional de la Vivienda, ya desde 1939, regula este tipo de edificaciones, de promoción oficial, con carácter imperativo y ámbito nacional. Se propone expresamente el bloque de doble crujía de inspiración higienista, el edificio exento y la liberación de los terrenos circundantes para el tráfico rodado, recomendándose el modelo de manzana Radburn.

Es curiosa esta elección de modelos urbanísticos modernos (que Terán explica por la elección personal del arquitecto-jefe ${ }^{2}$ ) si se tiene en cuenta la orientación política general, que preconizaba la tradición arquitectónica y urbanística. En todo caso es un hecho que el modelo se extendió por todas las ciudades, siguiendo las ordenanzas de la Obra Sindical Del Hogar. En casos como el que nos ocupa lo que hace la iniciativa privada es únicamente emular los polígonos promovidos por el Estado.

De todas formas hay que tener en cuenta que el modelo había sido conocido ya con anterioridad, en algunos de los planes de extensión de los años 30. Lo importante ahora es que pasan del papel a la construcción. Es de destacar asimismo que durante la década de los 50 publicaciones españolas de tanto peso como la madrileña Revista Nacional de Arquitectura juegan a la indefinición mostrando en sus páginas ejemplos de la más rotunda modernidad, junto a casticistas y pintorescas construcciones de cuño regionalista.

\footnotetext{
2 TERÁN, Fernando de: Historia del Urbanismo en España III, siglos XIX y XX, Cátedra, Madrid, 1999.
} 
Todo esto explicaría la elección formal de ese sorprendente proyecto para el barrio de La Luz en Avilés, que nunca se materializó tal cual. Al contrario, lo que se construyó fue lo contrario: un barrio pésimamente diseñado, de calidades escandalosamente ínfimas y sin dotación de equipamiento alguna. Un sitio ni para el trabajo, ni para el descanso, tampoco para el tránsito, menos para residir.

Sobre las necesidades sociales que generan la iniciativa hay que tener en cuenta la promoción, por parte de las grandes empresas, de barrios para alojar a los propios trabajadores que se hace habitual a finales del siglo XIX y principios del XX en Asturias a través de iniciativas vinculadas a tendencias más o menos paternalistas. Son los casos de la Sociedad Hullera Española con el poblado minero de Bustiello ${ }^{3}$, la Fábrica de Armas de Trubia o los proyectos urbanísticos de Duro-Felguera ${ }^{4}$. Reaparece esto en momentos posteriores, destacando las actuaciones de las primeras décadas del franquismo y las del desarrollo industrial.

Es preciso considerar que las empresas españolas lo que harán será paliar el déficit de vivienda a precios asequibles al que los recursos estatales no pueden hacer frente. En una primera etapa esta carencia obedece al tremendo crecimiento numérico del proletariado, que conllevará una concentración humana sin precedentes en torno a los núcleos fabriles que la Revolución

\footnotetext{
${ }^{3}$ ADAMS FERnÁNDEZ, Carmen: “El Modernismo en la arquitectura de la Sociedad Hullera Española", en Notas sobre el patrimonio industrial asturiano, CPR, Avilés, 2001; ADAMS FERNÁNDEZ, Carmen: "Bustiello: El pueblo ideal para el obrero perfecto", en La Asturias del cambio de siglo, Avilés, 2000; ADAMS FERNÁNDEZ, Carmen: "Bustiello: un ejemplo de rehabilitación integral del patrimonio industrial", en VV.AA. : Preservación de la arquitectura industrial en Iberoamérica y España, Granada, 2001.

${ }^{4}$ ADAMS FERNÁNDEZ, Carmen: "Las viviendas de Duro Felguera a principios de siglo", en Notas sobre el patrimonio industrial asturiano, CPR, Avilés, 2001
}

Industrial generará en diferentes zonas del país, siendo en concreto Asturias una de ellas. Durante la posguerra, sin embargo, el déficit de vivienda obrera estará además íntimamente relacionado con las consecuencias del conflicto bélico, y la sistemática destrucción de inmuebles que ocasionó. Y en la época del desarrollismo hemos de hacer necesaria referencia a los polos de atracción que supondrán las grandes factorías, como es el caso de ENSIDESA, en núcleos urbanos no preparados para un aluvión como el que habrán de soportar.

Intentando situarnos en el contexto español de la época ${ }^{5}$, hay que tener en cuenta que la demanda de alojamiento producida por una población inmigrante e insolvente será uno de los grandes problemas a resolver en las ciudades de posguerra. Si bien esta situación tiene precedentes en España ya desde el siglo XIX, ahora con la intensificación de la industrialización se agudiza. Además, los movimientos migratorios desde Andalucía, Extremadura y Castilla hacia el norte industrializado no sólo afectarán a Avilés, pues entre 1950 y 1960 la industrialización movió a más de un millón de personas desde esos lugares hacia Cataluña, País Vasco y Madrid.

Los inmigrantes a las grandes ciudades suelen generar barrios de chabolas periféricos que poco a poco producen espacio urbano. Junto a este crecimiento periférico, se produce en los centros de las ciudades españolas de la época inmediatamente anterior al desarrollismo de los 60 , una sustitución puntual de inmuebles, con el consiguiente incremento de altura y aprovechamiento volumétrico del solar, y el lógico cambio del aspecto arquitectónico. Se densifican y compactan además las manzanas de estos cascos históricos, que aumentan así

\footnotetext{
${ }^{5}$ TERÁN, Fernando de: Historia del Urbanismo en España III, siglos XIX y XX, Cátedra, Madrid, 1999.
} 
notablemente su población. Otra transformación urbana será la provocada por la expansión fuera de los límites de estos centros, que se ven desbordados siguiendo planes más o menos establecidos.

Para este crecimiento exterior en solares de grandes dimensiones se contaba con los polígonos: bloques de viviendas de gestión única y proyecto conjunto, realizados por entidades oficiales o patronatos diversos. En un primer momento serán de iniciativa pública, pero pronto la privada actuará en este ámbito por considerarlo un negocio de gran rentabilidad.

Y será ésta una forma muy importante que adopte el crecimiento urbano de las ciudades españolas. Se trata de un espacio que no es nuevo sólo porque aparezca entonces, sino porque obedece a una nueva forma de construir el espacio urbano: son conjuntos de bloques simples, independientes, de arquitectura unificada. Es una edificación abierta, discontinua y uniforme, frente a la tradicional manera de manzana cerrada y fachadas de gran heterogeneidad de la ciudad tradicional. De todas formas, en un principio esta curiosa adscripción a las teorías del Movimiento Moderno y la Carta de Atenas se realizará de forma ambigua, con bloques que se cierran sobre sí mismos. Destaca Fernando de Terán cómo "estas actuaciones oficiales adoptan pronto la nueva concepción del espacio del racionalismo europeo, cuando la arquitectura del Régimen no había despegado aún del herrerianismo imperial o del casticismo".

Volviendo al caso de Avilés resulta interesante reseñar como la idea de fijar la población obrera en las proximidades de la fábrica venía también de antiguo. En este sentido, habremos de referirnos a la ciudad como núcleo comarcal desde el punto de vista funcional, siguiendo a Guillermo Mo- rales $^{6}$, aun teniendo en cuenta que a veces se excederán los límites municipales.

Así, será pionera en esto de localizar la residencia de los trabajadores cerca de las instalaciones industriales la Real Compañía Asturiana de Minas con sus poblados de Arnao y Salinas para obreros y técnicos. Además, es destacable como Avilés es un núcleo poblacional donde tendrá gran incidencia en diversos momentos el levantamiento de barriadas obreras, resultando reseñable la eclosión producida a raíz de la instalación en los años 50 de ENSIDESA. Esto supondrá de hecho un hito en la historia urbana de la villa, que verá transformarse su morfología por completo, ya que hasta esa fecha el crecimiento se había desarrollado prácticamente sobre el plano preexistente, sin necesidades de expansión espacial. Surgirá entonces cerca de la fábrica un poblado modelo con equipamientos como es Llaranes y distintos barrios sin dotaciones de servicios, como La Luz.

Sorprende en Avilés el alto grado de conservación de los edificios y trazado tradicional del casco histórico. Es cierto que la sustitución tradicional del caserío fue un hecho a partir, sobre todo, de 1880; pero la elevada calidad de este tipo de construcciones de gusto ecléctico, modernista o regionalista, hace que esto no sea considerado por nosotros como una agresión al patrimonio, sino como una normal evolución de la ciudad, que aporta nuevos matices y enriquece la misma.

Lo que, afortunadamente, falta en Avilés es la irrupción en la parte antigua de la urbe, de edificios vinculados al desarrollismo de los años 50 o 60, o de actuaciones urbanísticas que inspiradas en planteamientos Haussmannianos eligiesen la apertura de grandes avenidas que rompiesen el

\footnotetext{
${ }^{6}$ MORALES MATOS, Guillermo: Industria y espacio urbano en Avilés, Oviedo, 1982.
} 
plano tradicional. Aquí la calle de La Fruta sigue siendo lo que era, también y acaso más La Ferrería, y los arrabales se distinguen perfectamente. Incluso Galiana ha sabido conservar sus soportales que algunos quisieron tirar, como se evidencia en las páginas del periódico $\mathrm{La}$ Voz de Avilés durante la última década del siglo XIX. No se llegó a ello aunque faltaba aún tiempo para que Roberto Pane hablase de la importancia de los conjuntos, en los que el mérito de los edificios estriba "justamente por estar juntos".

La explicación a esto hay que buscarla en dos cuestiones complementarias. Por una parte el que el crecimiento demográfico de Avilés durante la Edad Moderna e incluso gran parte de la Contemporánea no haya hecho preciso un incremento del plano de la ciudad. Por otra el que cuando sí fue necesaria una tremenda expansión, ésta se realizase alejada del núcleo originario, en barrios segregados y aislados entre sí, con amplias zonas baldías intermedias que en muchos casos ni aún hoy se han compactado.

De hecho, el verdadero y brusco cambio urbanístico en Avilés se producirá en los años cincuenta. Pero aún en 1950 la situación será más o menos similar a la de la etapa anterior. Habrá que esperar a la segunda mitad de la década para ver con nitidez el cambio.

Y esta radical transformación vendrá de la mano de ENSIDESA, que entra en funcionamiento en 1957, y de la atracción que la gran fábrica supondrá para trabajadores venidos de fuera de la región. Se abre entonces un nuevo periodo en la evolución urbana, caracterizado por un caótico crecimiento espacial para hacer frente a la urgente necesidad de acoger a la gran masa de población que llega en busca de trabajo. Además, otra característica de esta etapa urbanística será la fuerte segregación social de los distintos barrios. Serán a veces iniciativas de la propia empresa como el poblado de Llaranes, en otras ocasiones será de un particular como Domingo López en La Luz, aunque el destino era el mismo. Otra empresa, ENDASA, construyó también un poblado para sus trabajadores junto a la fábrica, en San Balandrán.

El caos que supuso para Avilés el crecimiento demográfico ocasionado por la implantación de ENSIDESA conllevará que el Estado acometa obras para polígonos de viviendas sociales. Según destaca Guillermo Morales $^{7}$ se caracterizan por su situación periférica, baja calidad de la construcción, déficit de equipamientos básicos y desconexión del resto del tejido urbano al que se une por una única vía de comunicación.

Centrándonos ya en el tema que nos ocupa hay que decir que hablar del barrio de La Luz supone necesariamente hablar de lo que pudo ser y no fue. $Y$ es que lo que aquí se hizo se puede considerar uno de los más flagrantes ejemplos de mal hacer urbanístico, de desprecio hacia la calidad de vida de los trabajadores. Al margen de las actuaciones de la etapa democrática, con anterioridad a ella, el que este barrio se convirtiera en un lugar habitable con zonas verdes, lugares de encuentro y zonas de paseo es consecuencia únicamente de la actividad y las presiones vecinales.

El barrio avilesino de La Luz es, cronológicamente, el segundo gran poblado en el que Ensidesa interviene para alojar a sus trabajadores ${ }^{8}$. El primero, con un planteamiento radicalmente opuesto había sido Llaranes. Y es que la fórmula ahora va a ser bien distinta, pues será un promotor priva-

\footnotetext{
${ }^{7}$ Morales Matos, Guillermo: Industria y espacio urbano en Avilés, Gijón, 1982

${ }^{8}$ MORALES MATOS, Guillermo: Industria y espacio urbano en Avilés, Oviedo, 1982.
} 
do, Domingo López Alonso, quien se encargue de su construcción, para más tarde venderlo a ENSIDESA. La empresa entonces ofertará los pisos a sus trabajadores en régimen de alquiler o venta.

Las obras comenzaron en 1957, cuando se empezaban a entregar las llaves de Llaranes, y no concluyeron hasta 1962.

La idea de un gran barrio residencial para Avilés se expone en 1955 al mundo como un paso adelante respecto al poblado de Llaranes recientemente erigido por ENSIDESA para sus trabajadores. Ahora ya no se trata, según el idílico proyecto, de constituir un entorno más o menos digno para los obreros de ENSIDESA. Lo que el promotor privado Domingo López Alonso, artífice de esta operación, plantea va más allá: una urbanización de 5.000 viviendas destinadas a una supuestamente floreciente clase media.

Sería un Nuevo Avilés dotado --tal como se recoge en las actas de un pleno municipal de febrero de 1955-- de "templo, escuelas, campo escolar de deportes, jardines, plaza de abastos, teatro-cine, tiendas y cuantas otras instalaciones y edificios públicos sean precisos".

En mayo de ese mismo año se llegó a exhibir una maqueta del nuevo barrio, que en palabras de Juan Carlos de La Madrid resultaba "más propia de un enclave turístico mediterráneo que del barrio obrero al que iba destinada" ${ }^{\prime 9}$. El poder público apoyó sin reservas esta iniciativa privada, pese a la inquietud e incluso oposición manifiesta de ciertos sectores de la sociedad avilesina, especialmente de los comerciantes del centro histórico de la villa. Éstos temían un desplazamiento de la actividad comercial hacia ese Nuevo Avilés, que conllevaría el

\footnotetext{
${ }^{9}$ MADRID, Juan Carlos de la: Avilés, una historia de mil años, Avilés, 1997
}

fin del pequeño comercio tradicional del casco viejo. A nosotros es cierto que esto nos sorprende, visto lo visto, pero es que entre el proyecto inicial y la realidad no hubo más relación que el nombre, y los temores de los comerciantes eran fundados, a la vista del folleto que Domingo López publicó para apoyar su iniciativa.

Esto se pone de manifiesto en la carta publicada en La Voz de Avilés de 21 de septiembre de 1955, firmada por la Cámara de Comercio, Industria y Navegación, y dirigida al ministro de Gobernación. En la misiva se manifiesta la oposición al nuevo barrio, por entender que "romperá definitivamente la estructura tradicional de la población". Si bien se entiende las urgente necesidad de vivienda, se propone un crecimiento racional de la villa en torno al casco histórico y no en un núcleo segregado, y se expresa el temor a que el nuevo núcleo modifique los precios del suelo, al modificar la posición del centro.

Y es que esto de desplazar los barrios obreros lejos del centro será una constante en el caso del Avilés de ENSIDESA. Lo que se logra es generar lagunas de suelo libre entre los nuevos asentamientos y el centro, lo que conllevará un inmediato incremento de precio de esas áreas, con lo que ello supondrá para el enriquecimiento de los promotores privados. Además es preciso mencionar que el Plan General de Ordenación de Avilés de 1956 quedó desvirtuado en pocos años, como consecuencia de modificaciones de todo tipo ${ }^{10}$.

El PGOU de Avilés, como los de otras ciudades, será el desarrollo de la Ley del Suelo (Ley sobre Régimen del Suelo y Ordenación Urbana), aprobada en 1956. Es un código urbanístico muy completo y bien articulado, perfectamente comparable a las

\footnotetext{
${ }^{10}$ MADRID, Juan Carlos de la: Avilés, una historia de mil años, Avilés, 1997
} 
leyes europeas de los años 40 que le habían servido de modelo. (italiana de 1942, francesa de 1943 y la británica de 1947). Aquí se definen como instrumentos los PGOU de ámbito municipal y los planes parciales que desarrollan partes de los anteriores. En general, los ayuntamientos no se sintieron especialmente vinculados a las nuevas directrices urbanísticas, como tampoco la Dirección General de Urbanismo, de la que dependían. Ello se tradujo en favorecer un desarrollo urbano hecho de iniciativas privadas fragmentarias y descoordinadas. De hecho no será hasta los años 60 cuando ayuntamientos y técnicos sean capaces de comprender los nuevos mecanismos y llevarlos a la práctica.

Domingo López obtiene en diciembre de 1957 licencia para construir 5.500 viviendas, con un proyecto del arquitecto madrileño Jacobo Romero Fernández, fechado en 1955 en Avilés. Sin embargo el proyecto inicial irá sufriendo modificaciones ${ }^{11}$, y al final lo que se ejecuta es otro, firmado por el arquitecto Antonio Urte Muguerza, quien se encargará asimismo de la dirección de obras.

Es destacable como durante la construcción del barrio, van surgiendo nuevas transformaciones, tendentes todas a abaratar y empobrecer la construcción, ya que según dice el arquitecto Urte con toda desfachatez: "se estima aconsejable adaptar las proyectadas construcciones del barrio de La Luz a las posibilidades económicas de los presuntos moradores".

En el proyecto inicial había distintos modelos de bloques, con pisos de diversas medidas, algunos que habrían superado incluso los 100 metros cuadrados (los más grandes construidos no pasarían de 70). El conjunto habría estado integrado por edifi-

${ }^{11}$ BOGAERTS, Jorge: El mundo social de ENSIDESA, Avilés, 2000. cios de distinto número de plantas, algunos alcanzando las 16. Entre los bloques se habría dispuesto frondosa vegetación: la idea de ciudad de Le Corbusier y el Funcionalismo, con sus edificios cruciformes exentos dispersos sobre un gran parque. No obstante aquí éste ya se reduce, incluso en el proyecto inicial, a unos pocos árboles.

Es curioso como la propuesta parece dirigirse hacia unos nuevos grupos sociales, distintos de los destinatarios de otras iniciativas como Llaranes. Ahora se trata de técnicos de ENSIDESA o de esos obreros de una empresa eterna y poderosa que la exaltación del Régimen equiparaba con otras categorías profesionales cuyos modos de vida eran hasta entonces inalcanzables para un trabajador medio. ${ }^{12}$ Así el 28 de agosto de 1959 el promotor declaraba en La Voz de Avilés: "El Barrio de La Luz constituirá una ciudad completa. Por tanto caben en ella habitantes de diversas zonas, aunque si prefiere podemos referirnos a la exacta clase media: profesionales liberales, técnicos de diverso grado, hombres de carrera, especialistas, obreros industriales, etc...".

$Y$ es que es cierto que los trabajadores de ENSIDESA constituían un grupo privilegiado respecto a otros colectivos profesionales asalariados de empresas privadas, ya que disponían de un sueldo seguro y de una jornada razonable, pero además de diversas ventajas sociales y de ocio. Incluso algunos empezaban a principios de los años 60 a disponer de su propio vehículo utilitario. Sin embargo, de ahí a pensar que el aparcamiento supusiese un problema a solventar en las décadas de los 50 o 60, parece que hay un abismo. Y digo esto porque en la propaganda del barrio se dice que: "El barrio de La Luz dispone de gara-

\footnotetext{
${ }^{12}$ MADRID, Juan Carlos de la: Avilés, una historia de mil años, Avilés, 1997
} 
jes suficientes y lugares de aparcamiento de acuerdo con el número de sus habitantes".

Pero no sólo es lo referente a los estacionamientos lo que evidencia un desfase total entre la realidad y estas propuestas tan preocupadas por el tráfico rodado que parten claramente de las preocupaciones del urbanismo progresista y el Movimiento Moderno. Hay que tener presente que Avilés se muestra por estas fechas incapaz de afrontar la demanda de vivienda surgida a raíz de la inmigración de gentes venidas de todas partes hacia ese sueño del trabajo estable y el salario digno, y lo que el proyecto plantea es casi una ciudad utópica destinada a no se sabe quien, en la que habría "zonas deportivas con campos reglamentarios de baloncesto y fútbol, canchas de tenis y otras instalaciones de esparcimiento... varias plazas independientes y pequeños parques infantiles". Al respecto señala Jorge Bogaerts que "los emigrantes recién llegados de los campos extremeños no parecen ser los mejores candidatos a jugar al tenis".

Nada de esto se plasmó en la realidad, convirtiéndose La Luz en paradigma de lo que no se debe hacer, en ejemplo de imprevisión. Porque frente a otras actuaciones urbanísticas tendentes a paliar el déficit de vivienda en Avilés, entre las que destaca Llaranes (que de hecho supuso el escaparate de la obra social de ENSIDESA), La Luz es lo contrario de lo que ha de hacerse. No hay aquí infraestructuras como hospital, parques, y mucho menos canchas de tenis.

Llama la atención cómo en el proyecto la oferta educativa es amplia y variada. Nada más lejos después de la realidad. Se dice así:

"La vida estudiantil en todos sus grados está totalmente asegurada. Para la enseñanza Primaria se han previsto varios grupos escolares situados en zonas de acce- so seguro, sin cruces peligrosos de calles y en sectores de visibilidad suficiente y circulación escasa."

Y continúa: "Como elemento decisivo para la población estudiosa, una Orden religiosa dedicada a la enseñanza regirá un importante colegio con capacidad para 1.600 alumnos de Bachillerato en sus dos grados, estudios de Preuniversitario e iniciación de carrera, además de los alumnos de Enseñanza Primaria. Servicios de internado mediopensionistas y externos, instalaciones pedagógicas modernísimas, campos de deportes y otras atenciones figuran también en este gran centro pedagógico.

Una escuela de Formación Profesional está prevista en los planes del poblado".

Casi nada, si consideramos que en 1962 todavía se andaba a vueltas sobre quién financiaría las escuelas y que cuando se empezó a habitar el barrio a principios de1963, aún no estaba resuelto el problema, y sólo se habían habilitado unas pocas aulas que no solucionaban nada. Destaca que aquí ENSIDESA declinó implicarse, frente a lo que había hecho en Llaranes, y al final las escuelas hubieron de ser municipales.

De hecho los Colegios Nacionales entraron en funcionamiento en el curso 196970. Hasta entonces la empresa transportaba a los escolares a los colegios de Llaranes, para intentar una imagen de igualdad entre ambos barrios, imagen evidentemente falsa e imposible.

Tampoco el centro de Enseñanza Media fue el de los interesados sueños de Domingo López. El colegio privado con piscina e internado quedó en Instituto de Enseñanza Media; aunque se tardó en saber quien afrontaría su coste, porque el promotor tenía claro que como mucho cedería terrenos. Al final se hizo cargo el Ministerio y el Instituto empezó a funcionar en el curso 1967-68. 
Respecto a los parques infantiles previstos, como era de prever nada de nada. $\mathrm{Y}$ así suma y sigue.

¿Qué pasó entonces con aquella idea de convertir La Luz en el nuevo centro comercial de la villa?, ¿Qué ocurrió con la desconfianza de la Cámara de Comercio?. Pues, para hacernos una idea, en diciembre de 1963 se inaugura el economato, por cierto con bendición eclesiástica incluida. Es decir, frente a complejo comercial de lujo, economato para productos básicos.

Otra carencia importante en la plasmación real del barrio era la de templo, pero esto se subsanará rápidamente. Y es que tal como señala Bogaerts "corrían tiempos en que podían obviarse los colegios, desdeñarse los parques infantiles, o ignorarse las instalaciones deportivas, pero la empresa no podía ser ajena a la Iglesia".

En cuanto a los bloques de pisos el resultado a la vista de lo antedicho es previsible: nada que ver con el proyecto. Así entre 1957 y 1962 se construyeron 2.056 viviendas de entre 45 y 63 metros cuadrados de superficie.

Así, el resultado inicial fue tremendamente duro: 89 bloques impersonales para vivir en pisos, en ocasiones bajos, de pequeñas dimensiones, ejecutados con materiales de escasa calidad, cuyas deficiencias fueron denunciadas por los vecinos ya desde un principio. Bloques además ubicados sin un entramado urbano, sin plazas ajardinadas, sin aquella vegetación exuberante del proyecto. Un barrio sin equipamiento, una ciudad dormitorio como tantas.

Pero, precisamente esta circunstancia, la ausencia de paternalismo hacia La Luz, hace que los habitantes del barrio se mostrasen más reivindicativos, más dispuestos a denunciar sus problemas que los vecinos de otros poblados mejor dotados, pero también más controlados por la empresa. En este sentido es destacable la labor de la parroquia de San Pablo de La Luz con su Boletín informativo Barrio de La Luz que se publica a partir de diciembre de 1963.

Sobre la escasa implicación de ENSIDESA en el barrio, si se compara una vez más con Llaranes, es reseñable como ya en 1960 se efectúa la compra total del barrio -2.056 viviendas-- por parte de la empresa, la cual sin embargo no se hace aquí cargo de infraestructuras o equipamientos.

Así, es claro que el resultado, que a la vista está, nada tuvo que ver con el proyecto inicial ni con los postulados del Movimiento Moderno. Y ello no únicamente en lo referente a cuestiones de índole formal, sino también en lo que afecta a usos, funciones y objetivos de incremento de la calidad de vida de los trabajadores, cuestiones todas que brillan aquí por su ausencia. 

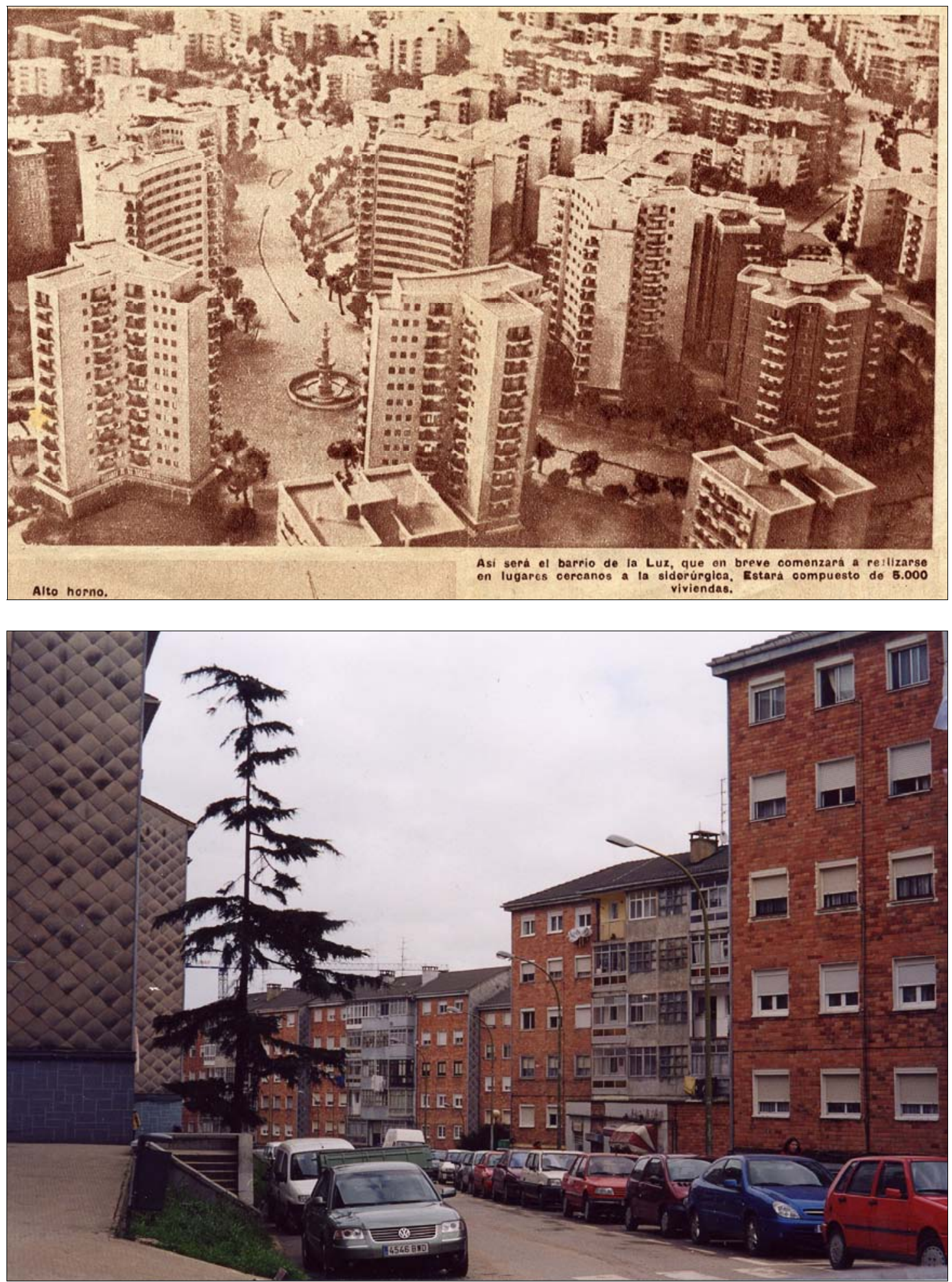

- Fig. 1. Barrio de La Luz. Proyecto inicial (arriba centro)

- Fig. 2. Barrio de La Luz en la actualidad (abajo centro) 